\title{
Building Up Pre-Service Mathematics Education Students' Geometry Competency Based On Visual
}

\author{
Mohamad Rif'at \\ Universitas Tanjungpura \\ Pontianak, Indonesia \\ mohamad_rifat@yahoo.com
}

\begin{abstract}
The researcher presents data from teaching and learning series by a group of pre-service Mathematics education students from 2012 to 2014. The question addressed is: How do students of geometry come to think visually? The researcher gave students a written test to ascertain their visual levels and acquisition degree of spatial abilities. Some students volunteered to work in small groups, whose task was to determine the nature of the object by asking questions about it. The purpose of the instruction was to investigate information on students' visual thinking and geometry competencies in solving some geometric problems in class. The purpose of the group discussions was to elicit information on the students' visual perception and image formation in describing several geometric figures. Visual representations in the identification of the general view of geometric figures and to be manipulated figures. A common scheme used by students was identified and the identification consisted of describing and imagining simple geometric forms in terms of simpler geometric parts. All students were given a written test to ascertain their categories of spatial abilities. Whilst the visual pattern generally reflects the Geometric Thinking Models, an exploration at each levels compared to the written tests indicated that those levels are not hierarchical. Generally, visual perception correlates with a spatial, but the image formation seems to require a different sort of ability.
\end{abstract}

Keywords-Geometric Figures, Visual Thinking, Visual Representation, Visual Perception, Image Formation, Spatial Ability

\section{INTRODUCTION}

Mathematics in teaching and learning until now is mainly analytics with their vivid contents, i.e. symbolic, mechanistic and handling only for proving without meaning which makes students feel confused. According to this state of the art, some difficulties are discovered, namely: (1) in applying procedures, concepts, and principles, (2) in making deductive reasoning, (3) in manipulating algebraic expression, (4) in formulating languages and logic, (5) in understanding analytic forms, and (6) in constructing mathematics formally [1][2][3][4][5]. Those conditions must be anticipated, the power of problem solving primarily starts from visual intuitive level to generate thinking process and better for analytic levels [6]. After visual thinking pattern is constructed, ability to develop geometric principles will be pointed up. Doing maths from visual brings out more believed system than others [7]. Students who tend to use analytic style do not show good understanding, but only for routinity and fun. The results are also explained by [8] learning maths analytically which is critical and cannot become powerfull indicator for problem solving [8].

This research was to show the strength of visual for building up geometry competencies, especially in solving problem. Visual is used to enhance students' performance in maths cognitive process (metacognitive). This research used a developed model called Rive's Model based on thinking activities in visual [3]. The model gradually generates geometry competencies according to thinking levels in and from visual manner that bring out a process of how to know and develop visual information in stablity and application.

The adequate visual representation is not just as a representation, but for ability in studying maths generally. The solution method used by students is based on assignments reflecting visual orientation [9]. The results of research in cognitive psychology also show the core of visual ability which has significant role in solving geometry problems. For instance, some research results according to visual thinking as follows: (a) visual imagery could be used in developing mathematics teaching and learning, (b) visual amplifies mathematics power and reasoning, and (c) visual stimuli can be reexamined easily when students want to generate and develop analytic concepts based on their perceptual [10][11].

\section{RESEARCH QUESTIONS}

Mathematics visualization is still used as a discrete tool to mathematical thinking when observed in a holistic needs of learning. Visual aspects are often not deduced from figure or not manipulated, but are always back to algebra manipulation due to the figure. The performance calls an analytics solution [12][13] or symbolic representation [3].

The question to be addressed is: How do students come to understand geometry problems based on visual representation and visual thinking? Which means do students themselves use to describe, relate, explain, construct and understand, to the properties of geometric figures, as distinct from being taught those properties?

This research focused on the two processes of visual thinking and visual representations. In the mathematics education literature, these two processes are often taken to be synonymous, but in this research visual representations are different from visual thinking. An excellent discussion of the different ways visualization and thinking power have is used by various people in mathematics education. The researcher 
investigated the two terminologies to be used in this research that they are sharing the meaning for different competencies. On the other hand, a single term, "visual representation", may have different meanings due to ability for solving problems.

There is evidence [3] that students can build visual representation from verbal descriptions and that patterns formed as a result of these descriptions use visual sequences. Deduction based on analytics reduces mathematical understanding, and also show many missconceptions or far from accuracy. Students count an integral without visual thinking showing substansial error [3][14].

The error in making conclusion from visual representation is called oblique effect, i.e. caused by perceptual effect due to visual process and activity [10]. The main problems are: (1) figure setting considered by constant object, (2) information on visual objects assumed by students, (3) students still come to make analytic solution from geometric figure, and (4) most students need formula rather than contructing other visual pattern in solving problem [3].

In this research, a series of learning activity was done to explore and overcome any obstacles in using figures for solving visual problems without 'suddently' translate to analytics representation. We call that learning is based on visual thinking ability.

\section{THEORETICAL FRAMEWORK}

The concepts of geometry and visual pattern are relatively illustrative: What is said might be a constructed feature for someone else. Seeing some features of objects are inherently deep features [15]. Unfortunately, geometry representation in problems are just as an aid tool, still far from doing maths [3]. To hypothesize, when a person examines geometric object and attempts to describe those analytically, two things alternate: (a) algebraic and (b) a belief of their visual perception. It is just this alternation, in my view, that produces visual representation. For example, consider the following test. Consider a rectangular triangle with sides of 30 and 40 . If we draw the median and the bisector from the largest acute angle, we obtain a new triangle. The next task is to determine the shading area of the triangle.

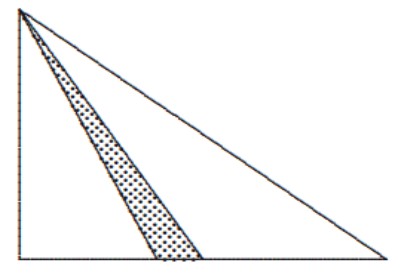

Fig. 1. Shading area of triangle

The test item actually, in my point of view is not so good for building up mathematics ability, especially from geometry. It is more for algebraic with full mathematics content, or analytical solution. The item also comes to disequilibration in students' belief system because of the representation. Therefore, fluency of mathematical expression is not necessarily connected to the adequately visual thinking. In the example is : (1) area (2) bisector, (3) median, and (4) accuration of position.

The results of the test show that $20.97 \%$ students gave wrong answer and $53.53 \%$ did not give an answer at all (blank), or only $25.50 \%$ gave right answer. They tend to do maths with analytics representation, influenced by their perception come to wrong solution. Other students construct their belief that, in that case, the median dan bisector cross base segment as close as possible. The visual thinking convinces them that both areas are not so much different and bring them to the right answer. The students' perception is the same when they face with similar problem, for example, to count the percentage of the shaded area in the rectangle below. For that test item, $27.73 \%$ students gave wrong answer, and $20.25 \%$ left it blank.

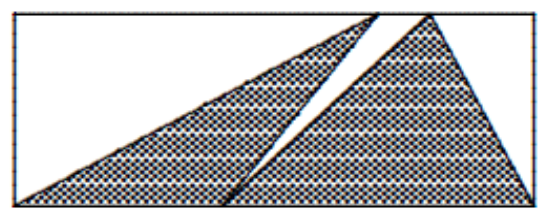

Fig. 2. Shaded area in the rectangle

In the mathematics education literature, a significant distinction is drawn between visual thinking and visual representations. The problem of what a visual representation is has been a question that has engendered much debate. Visual formation is dependent on high level visual thinking. This research was concerned with identifying mental processes conscious and especially unconscious- that underlie expert learning, thinking and performance in geometry. This research method was based on Algo Heuristic Theory that represents a system of techniques for getting inside the mind of expert learners and performers which enable one to uncover the processes involved. Once uncovered, they are broken down into their relative elementary components, namely mental operations and knowledge units, which can be viewed as a kind of psychological units. Performing a task or solving a problem always requires a certain system of elementary knowledge units and operations.

The other theoretical frameworks are cognitive flexibility and Ausubel's theory. The first one focuses on the nature of learning in complex and ill-structured domains. Ausubel's theory is concerned with how individuals learn large amounts of meaningful material from textual presentations in a school setting (in contrast to theories developed in the context of laboratory experiments). A primary process in learning is subsumption in which new material is related to relevant ideas in the existing cognitive structure on a substantive, nonverbatim basis. Cognitive structures represent the residue of all learning experiences; forgetting occurs because certain details get integrated and lose their individual identity.

The theory is largely concerned with transfer of knowledge and skills beyond their initial learning situation. For this reason, emphasis is placed upon the presentation of information from multiple perspectives and use of many case studies that present diverse examples. The theory also asserts that effective learning is context-dependent, so instruction needs to be very specific. In addition, the theory stresses the importance of constructed knowledge; learners must be given 
an opportunity to develop their own of information in order to properly learn.

There are classes of problems for which it is necessary to execute operations in a well structured, predefined sequence (visual problems). For such problem classes, it is possible to formulate a set of precise unambiguous instructions as to what one should do mentally in order to successfully solve any problem belonging to that class. There are also classes of problems (creative or heuristic problems) for which precise and unambiguous sets of instructions cannot be formulated. For such classes of problems, it is possible to formulate instructions that contain a certain degree of uncertainty (heuristics).

The theory suggests that all cognitive activities can be analyzed into operations of an abstract, semi-abstract, visual heuristic, or semi-visual heuristic nature. Once discovered, these operations and their systems can serve as the basis for instructional strategies and methods. The theory specifies that students ought to be taught not only knowledge but the image and visual thinking heuristics of experts as well. They also have to be taught how to discover perception and heuristics on their own. Special emphasis is placed on teaching students mental operations and heuristics which make up general methods of thinking.

With respect to sequencing of instruction, the researcher proposed a number of strategies, the most important of which is a thinking process method. This method applied to teaching a system of cognitive mental operations by teaching the first representation and operation, then the second which is practiced with the first, and so on. From an educational perspective we wish to make a clear distinction between these two interrelated processes. This is because whilst visual formation is indeed dependent on visual thinking. Its development is not simply a corollary of the development of visual representation. Something different seems to be involved. In the context of geometry, it is an ability to integrate local and global features of a geometric object.

Visual thinking and patterns are strongly linked in that they utilize similar brain mechanisms, and are highly dependent on visual perception [16][3]. However the development of image representations of objects seems to require something else, different from visual perception. Perception of objects such is a complicated process of making sense of visual and tactile data. In forming perceptual representations students actively manipulate objects seeking relevant data such as the types of faces, the number of faces, and how the faces fit together to form the global object for solving problem.

The literature on transformation of mental images makes clear that motor subsystems of the brain are involved [16]. However, as far as we can ascertain there is no substantial evidence that motor subsystems are involved in image formation. It was as if the hands, in particular, were reflecting an internal attempt to build the image in the mind.

Perception is usually thought of as an individual matter. From a mathematical point of view, information is for solving problem and could come (almost all) in pre-formed categories or representations [3]. Thus, flexibility of mathematical expression is not necessarily connected to abstraction of thought. It's true that clear, construct visual pattern can be, and often is, an important aid to understanding. However, visual and thinking visual representations can also get in the way of mathematical understanding.

\section{RESEARCH METHOD}

The researcher administered 100 pre-service Mathematics education students a written test to ascertain their visual levels and degree of acquisition of visual representations [3]. The written test contained 5 questions described below. Table 1 shows Inter-rater reliability. The estimation was based on the correlation of scores between/among raters who rate the same item. The Kuder-Richardson inter-term reliability was used for each question.

\section{TABLE I. KUDER-RICHARDSON INTER-TERM RELIABILITY COEFFICIENTS}

\begin{tabular}{|c|c|}
\hline Question & Reliability \\
\hline 1 & 0.64 \\
\hline 2 & 0.87 \\
\hline 3 & 0.66 \\
\hline 4 & 0.91 \\
\hline 5 & 0.72 \\
\hline Overall & 0.76 \\
\hline
\end{tabular}

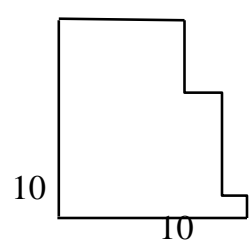

Fig. 3. Question 1: Asking students to count the perimeter

This question explored conceptualization visual process. It was associated with constancy of objects in space, level 1 of mathematics ability. The students recognised that the figure had variant position. These properties were compared between figures which represent the square.

On question 2 (comprehention of visual methods), the students were asked to count diameter from figure presented. The diameter of a circle with center $\mathrm{m}$ is $110 \mathrm{~cm}$. A point $\mathrm{p}$ lying on a chord divides the chord in pieces of 30 and $60 \mathrm{~cm}$. Then equals ....

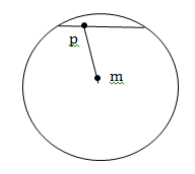

Fig. 4. Question 2: Comprehention of visual methods

This question was related to level 2 of visual representation and method grounded by a comprehension. It explored students' ability to understand the representation, figure completion, and figure assembly. This involved 
organizing two dimensional figures to obtain a new figure in solving the problem.

On question 3 (selecting correct visual processes), the students were required to select correct visual processes by their appearance and link with position-in-space perception, namely, that students can determine the relationship of one shape to another. The students were requested to recognize the equivalence of different views to successfully complete the figure and then to count the cosine of the top angle $\alpha$ of the one of the lateral faces.

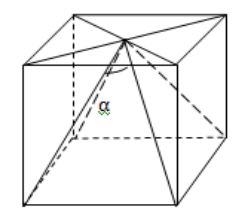

Fig. 5. Question 3: Selecting correct visual processes

On question 4 (application of visual facts), the researcher investigated the ability to apply visual facts for solving problem as follow. In Fig. 6, a square, a quarter of a circle, a diagonal of the square and a line segment that joins a vertex to the midpoint of a side exist. The students needed to compare the areas of $\mathrm{A}, \mathrm{B}$, and $\mathrm{C}$ of the indicated parts.

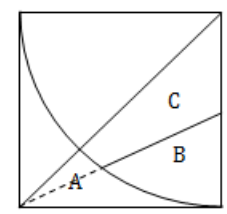

Fig. 6. Question 4: Application of visual facts

The objective of this question was for the students to apply and describe the figures' properties by the shape and differences, recognize the certainity of the shapes. This question was related to visual facts and explores the ability to relate the features of one shape to the others.

On question 5 (visual sequencing), the researcher explored the visual sequencing by a common set of shapes and properties. This question was linked with five visual representations and Rive's Model ground perception, the ability to sequence a specific figure by their shapes. The students were asked to count the shortest path along the surface from a sequence of similar and/or non similar figures, i.e. : two ants are situated on opposite vertices $\mathrm{A}$ and $\mathrm{B}$ of an object shaped like a regular icosahedrons, with edge 1 (as shown in the figure below).

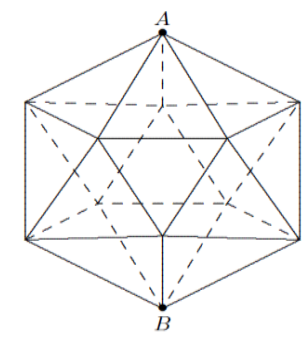

Fig. 7. Question 5: Visual sequencing
By asking the students their argument they were stimulated in thinking analytically about shapes needed. They also were asked their argument if there was only one such path or to give the different properties if there was more than one path.

\section{RESULTS AND IMPLICATIONS}

A model of Rive's visual thinking was used to assign the students to a specific level of visual within each level of visual thinking [17]. The results together were also assigned to mathematics abilities and partly are shown below. Note that a level of Conceptualizing Visual Processes, for example, means a student who has attained the level and is in building to a level of visual thinking.

TABLE II. INTERCEPTS OF VISUAL REPRESENTATION AND VISUAL THINKING

\begin{tabular}{|l|c|c|c|c|}
\hline \multicolumn{1}{|c|}{$\begin{array}{c}\text { Visual } \\
\text { Representa } \\
\text { tion }\end{array}$} & \multicolumn{3}{|c|}{ Visual Thinking } & \\
\cline { 2 - 5 } & $\begin{array}{c}\text { Visual } \\
\text { Reasoning }\end{array}$ & $\begin{array}{c}\text { Inferential } \\
\text { Reasoning }\end{array}$ & $\begin{array}{c}\text { Deductive } \\
\text { Reasoning }\end{array}$ & $\begin{array}{c}\text { Decision } \\
\text { Making }\end{array}$ \\
\hline $\begin{array}{l}\text { Conceptuali } \\
\text { zing Visual } \\
\text { Process }\end{array}$ & Precise & Adequate & Precise & Precise \\
\hline $\begin{array}{l}\text { Comprehens } \\
\text { ion of } \\
\begin{array}{l}\text { Visual } \\
\text { Methods }\end{array}\end{array}$ & Adequate & Insufficient & Insufficient & $\begin{array}{c}\text { Inappropria } \\
\text { te }\end{array}$ \\
\hline $\begin{array}{l}\text { Selecting } \\
\text { Visual } \\
\text { Processes }\end{array}$ & Precise & Adequate & Precise & Precise \\
\hline $\begin{array}{l}\text { Aplication } \\
\text { of Visual } \\
\text { Facts }\end{array}$ & Adequate & Insufficient & Precise & Adequate \\
\hline $\begin{array}{l}\text { Visual } \\
\text { Sequencing }\end{array}$ & Insufficient & Inappropriate & Precise & Precise \\
\hline
\end{tabular}

This research had assigned each levels of visual representation to stage of visual thinking respectively. I actually had difficulties with a clear determination of any level for students, for the following reasons. A student is in transition between levels Conceptualizing Visual Process and Comprehension of Visual Methods. However, another student also showed aspects of attainment of Selecting Visual Processes. The first student showed evidence of transition between levels two and three. However the student was not accurate on question 3, and did not show complete attainment of Comprehension of Visual Methods, i.e. determining the relationship of one shape to another. The students successfully completed the figure and then counted the cosine of the top angle $\alpha$ of the one of the lateral faces, but were not accurate in distinguishing visual facts when constructing shapes.

Visual representation is dependent on, but different from visual thinking. Although representation and thinking rely on building up geometry competencies, those together as a whole linked to mathematics abilities are not used identically in mathematics problems. In particular, or representations contain information that are already organized into analytics that have been previously interpreted. In contrast, in visual thinking one must organize the input from scratch and match it to stored; one does not know in advance what the object is likely to be.

Visual thinking of geometry objects is often accompanied by tactile representation. These two forms of visual or spatial ability integrate to allow a student a visual-tactile pattern of an object. A need to describe this perception can crystallise 
perception in striking ways. Students with a very good visual thinking had been answering questions about selecting correct visual processes and trying to describe it just by visual. However, other students had particular difficulty in forming an image of the object, so they tried to describe it differently. They began the description and suddenly perceived the object using cosines rule, something that had not seen visual process.

In exercising their ability to form images, the students utilized perceptual units that have been previously interpreted. These perceptual units were triangles, rectangle triangle and piramid. Without such pre-digested perceptual units the students would not be able to form such complicated images at all as Kosslyn (1996) [16] indicates.

According to Rive's Model in visual thinking, four elements of those due to mathematics abilities in visual manners were also observed, i.e. constancy of objects in space, spatial conservation, comprehension of visual relations, inferential memory, and visual reasoning and logic. Schematically, interrelationship among those are as follows.

TABLE III. RIVE's Model OF VISUAL THINKING IN VisUAL MANNERS

\begin{tabular}{|l|c|c|c|c|c|}
\hline \multirow{2}{*}{$\begin{array}{c}\text { Visual } \\
\text { Thinking }\end{array}$} & \multicolumn{4}{|c|}{ Mathematics Abilities: Building up Geometry Competencies } \\
\cline { 2 - 6 } & $\begin{array}{c}\text { Constancy } \\
\text { of objects in } \\
\text { space }\end{array}$ & $\begin{array}{c}\text { Spatial } \\
\text { conserv } \\
\text { ation }\end{array}$ & $\begin{array}{c}\text { Comprehensio } \\
\text { n of visual } \\
\text { relations }\end{array}$ & $\begin{array}{c}\text { Inferentia } \\
\text { l memory }\end{array}$ & $\begin{array}{c}\text { Visual } \\
\text { reasoni } \\
\text { ng and } \\
\text { logic }\end{array}$ \\
\hline $\begin{array}{l}\text { Visual } \\
\text { Reasoning }\end{array}$ & Insufficient & $\begin{array}{c}\text { Insuffi- } \\
\text { cient }\end{array}$ & Insufficient & $\begin{array}{c}\text { Insuffi- } \\
\text { cient }\end{array}$ & $\begin{array}{c}\text { Insuffi- } \\
\text { cient }\end{array}$ \\
\hline $\begin{array}{l}\text { Inferential } \\
\text { Reasoning }\end{array}$ & Adequate & $\begin{array}{c}\text { Insuffi- } \\
\text { cient }\end{array}$ & Inappropriate & $\begin{array}{c}\text { Inappro- } \\
\text { priate }\end{array}$ & $\begin{array}{c}\text { Inappro } \\
\text { priate }\end{array}$ \\
\hline $\begin{array}{l}\text { Deductive } \\
\text { Reasoning }\end{array}$ & Precise & $\begin{array}{c}\text { Inappro } \\
\text { priate }\end{array}$ & Insufficient & $\begin{array}{c}\text { Insuffi- } \\
\text { cient }\end{array}$ & $\begin{array}{c}\text { Insuffi- } \\
\text { cient }\end{array}$ \\
\hline $\begin{array}{l}\text { Decision } \\
\text { Making }\end{array}$ & Insufficient & $\begin{array}{c}\text { Insuffi- } \\
\text { cient }\end{array}$ & Precise & Adequate & $\begin{array}{c}\text { Inappro } \\
\text { priate }\end{array}$ \\
\hline
\end{tabular}

Most of the students tend to solve problems without considering elements of visual thinking. The student with good mathematics abilities, but difficulties with visual thinking demonstrated obstacles in solving of complex geometry forms. She described the two-dimensional faces, and perceived that this figure was constructed in a sequencial process. Another student showed no evidence of visual thinking of the 2dimensional figure to a formed triangle. Their visual perception appeared to be stimulated by distance concept, and not by enough investigation. The student speculated that the visual representation was really trace edges of part of icosahedrons. A difficulty with visual thinking will generaly caused a difficulty with mathematics abilities. However, it is quite possible to have good mathematics abilities, yet still have relatively difficulty in visual thinking. The problem seems one that besets all students of mathematics, and it is the problem of establishing repeatable units: in this case, repeatable visual.

Given that image formation is dependent on visual, it is difficult to reconcile this question about cosines of alpha that was constructed but a moment ago. This might indicate a problem with inferential memory, but even so, it still indicates that the image was far from permanent. However, one of the students was clearly capable of visual reasoning and logic. The student explains that if one puts a triangle in a fixed position, the required shape would be formed. The student did not take into account that just the lateral faces of a square would change from cube to a pyramid. This was clear however to the student, who was determined on the written test to be at the level. She demonstrated an ability to understand the logic of the situation which, infered that, came from a mental image of a cube being pushed laterally.

Those seem to indicate that visual thinking, whilst highly dependent on good visual, develops in different ways. As we have mentioned earlier, the problem of visual thinking of an object such as a icosahedrons is one of integrating local and global features, whilst the problem of high visual level sufficient to describe it to mathematics abilities, is that of misappropriating and manipulating objects. It seems that students' analytic skills were at high order but the corresponding visual thinking skills were not so well developed.

There are two ways in which students could have mentally constructed a representation of an object. One is by generating a perception of a seen physical object being sheared. The other is by manipulating the mental image in a novel perception. According to Rif'at (2001, p. 67) [3] such transformations are often carried out by instructions from the imaging of the brain. Generally the ability to form multiple part of an object, without co-ordinate spatial relations, is dependent on the visual representations of previous experiences.

In this study we also observed numerous instances of students imaging and constructing a triangle to count lpm] (question 2) from different view points. For example, the students inspected the line segment as long as line from $m$ to a point in the circle like radius. The literature on transformation of mental images makes clear that image perceptions (visual patterns) are involved. However, as far as we can ascertain there is no substantial evidence that inferential reasoning was involved in image formation. We observed many instances of inferential reasoning associated with image pattern. This inferential reasoning ability did not seem peripheral to the formation of visual images, but appeared, to us, to be a natural result of a student trying to 'push' mentally construct an image. About 57.84\% of students did not have any answer (or blank), $14.24 \%$ had wrong answer, and only $27.93 \%$ gave right answer.

According to question 5, 73.53\% of students gave wrong answer. Only $2.35 \%$ gave rightright, and $24.12 \%$ did not give any answer (blank). The distribution of the answer was also good to be known, i.e. $64.45 \%$ of students had the answer $\sqrt{3}+1,3.53 \%$ had $3,1.93 \%$ had $\frac{3 \sqrt{2}}{2}$, and $3.63 \%$ gave the answer $\frac{3 \sqrt{3}}{2}$. The distribution show students' perception about

an icosahedron away from the body of the geometry form (decision making). They appeared to count the shortest path along the surface without a visual thinking understanding (or deductive reasoning) from visual.

The cases also gave confirmation as the students were trying to describe the formation of mental images. This activity was quite different to mathematics activity we observed in visual representation and thinking, and seems to be a significant aid to students in their attempts to construct a coherent mental image. Its origin was unclear, however our hypothesis was that it was a significant, but not necessary, component in the integration of features of an unseen 3- 
dimensional object. For instance, their visual representations were related to making a way just what they see (answers for 3 and $\sqrt{3}+1$ ). The students who counted the shortest way that equal to $\frac{3 \sqrt{3}}{2}$ indicated how they were thinking of the same altitude in equidistance triangle. Or, the students seeing a shape appears to relate to the appearance of part of a 2-dimensional face of the object.

Thus, the visual representation appear to be related to dimensionality and spatial positioning, as well as to the integration of the object. Perception is usually thought of as an individual matter: a question of an active intelligence, paying attention, and gaining information through the senses. So what is it that stimulates a person to act, and to begin to order their inferential memory. Another student (who gave the answer $\left.\frac{3 \sqrt{2}}{2}\right)$ responded with lack accuracy in visual reasoning and

logic (spatial reasoning) which affected their perception. For example, the student showed an understanding that the distance was straight line from point to point.

Question 3 showed the evidence that the students perceived and described the constructed of the shape in many variations. About $26.19 \%$ of students gave wrong answer and $39.20 \%$ did not give any answer (blank). They perceived the cube in various ways apparently looking for pyramid. However, students' perception was still relatively insufficient. In answering the question, the students placed pyramid to leave the cube band. We inferred that was precisely at this point that the students obtained a perception of the lateral faces as equidistance triangle. This perception was prompted by the other students trying to reconcile their images of the pyramid with the same length for cube's side and side of lateral faces. In this sense,

Based on question 4 (application of visual facts), we investigated the ability to apply visual facts for solving problem, i.e. students could compare the areas of A, B, and C of the indicated parts. The results were that $24.54 \%$ of students gave wrong answer, 32.35 gave right answers, and $43.10 \%$ with blank sheets. The students with the answer of $\mathrm{C}<\mathrm{A}<\mathrm{B}$ indicated a permanent image due to the representation, so did others who gave $\mathrm{A}<\mathrm{C}<\mathrm{B}$. Where were their visual thinking? and how did they build their mathematics abilities? According to its shape, actually the parts of the figure look different, but student's perception make difficulties. Their visual thinking based on visual image in term of optical illutive.

We expected that attainment in Rive's Model levels would correlate each of visual representation and/or visual thinking to mathematics abilities in geometry. Whilst there does seem to be a general correlation between visual thinking and mathematics abilities, the same does not seem to be the case with regard to visual representation. The evidence we have presented suggests that students with high conceptual levels can have difficulties with visual representation (or in represent visual formation), whilst students with low conceptual levels can successfully form complex geometric problems. For example, a student was determined to be operating at deductive reasoning, with in appropriate comprehension of visual relations. This student also had good comprehension of visual methods yet encountered considerable difficulties in the formation of images of icosahedrons. Another student was at constancy of objects in space competencies yet this student successfully formed a visual sequencing of a triangle faces of icosahedrons.

In Table IV, we provide some evidence that there is a general correlation between visual representation and visual thinking toward mathematics abilities.

TABLE IV. CORRELATION BETWEEN VISUAL RERESENTATION AND VISUAL THINKING

\begin{tabular}{|c|c|c|c|}
\hline Table Head & $\begin{array}{l}\text { Visual } \\
\text { Thinking } \\
\text { Level } \\
\end{array}$ & $\begin{array}{l}\text { Mathematics } \\
\text { Abilities }\end{array}$ & Evidence \\
\hline $\begin{array}{l}\text { Conceptualizing } \\
\text { Visual Process }\end{array}$ & 1 & Very good & $\begin{array}{l}\text { Students recognize } \\
\text { the figure has } \\
\text { variant position. }\end{array}$ \\
\hline $\begin{array}{l}\text { Comprehension } \\
\text { of Visual } \\
\text { Methods }\end{array}$ & $1 \rightarrow 2$ & Good & $\begin{array}{l}\text { Students perception } \\
\text { grounded by a less } \\
\text { comprehension. }\end{array}$ \\
\hline $\begin{array}{l}\text { Selecting Visual } \\
\text { Processes }\end{array}$ & $2 \rightarrow 3$ & Enough & $\begin{array}{l}\text { In general, students } \\
\text { can determine the } \\
\text { relationship of one } \\
\text { shape to another, } \\
\text { but still have } \\
\text { difficulties to } \\
\text { successfully } \\
\text { complete the figure } \\
\text { and to count. }\end{array}$ \\
\hline $\begin{array}{l}\text { Aplication of } \\
\text { Visual Facts }\end{array}$ & $3 \rightarrow 4$ & Good & $\begin{array}{l}\text { Students could to } \\
\text { apply and describe } \\
\text { the figures' } \\
\text { properties by the } \\
\text { shape and } \\
\text { differences, } \\
\begin{array}{l}\text { recognize } \\
\text { certainty of the } \\
\text { shapes. }\end{array}\end{array}$ \\
\hline $\begin{array}{l}\text { Visual } \\
\text { Sequencing }\end{array}$ & 4 & Adequate & $\begin{array}{l}\text { Students' } \\
\text { argumentations } \\
\text { were stimulated in } \\
\text { thinking analytically } \\
\text { about shapes } \\
\text { needed. }\end{array}$ \\
\hline
\end{tabular}

This correlation is suggestive only because we did not have identical information for each student. Nevertheless, we know about different types of visual representation, visual thinking and mathematics abilities of geometry problems, and the development of these types. In this research, the students (all of who had completed mathematics degrees) exhibited geometry abilities, as in Table $\mathrm{V}$.

TABLE V. CORRELATION BETWEEN VISUAL RERESENTATION AND VISUAL THINKING

\begin{tabular}{|l|l|l|}
\hline \multicolumn{1}{|c|}{$\begin{array}{c}\text { Indicators for mathematics } \\
\text { competencies }\end{array}$} & $\begin{array}{l}\text { Visual } \\
\text { Representati } \\
\text { on }\end{array}$ & $\begin{array}{l}\text { Visual } \\
\text { Thinking }\end{array}$ \\
\hline $\begin{array}{l}\text { Symbolization : simplification } \\
\text { and generating }\end{array}$ & $*$ & $*$ \\
\hline Inferential Process & $*$ & $*$ \\
\hline Consistency & & + \\
\hline Completing & & + \\
\hline Potencial and perceptual & & - \\
\hline
\end{tabular}




\begin{tabular}{|l|l|l|}
\hline \multicolumn{1}{|c|}{$\begin{array}{c}\text { Indicators for mathematics } \\
\text { competencies }\end{array}$} & $\begin{array}{l}\text { Visual } \\
\text { Representati } \\
\text { on }\end{array}$ & $\begin{array}{l}\text { Visual } \\
\text { Thinking }\end{array}$ \\
\hline Belief & & + \\
\hline $\begin{array}{l}\text { Deductive logic and logical } \\
\text { processes }\end{array}$ & $*$ & $*$ \\
\hline $\begin{array}{l}\text { Mathematical insight and } \\
\text { mathematical precision conceptual }\end{array}$ & $*$ & $*$ \\
\hline $\begin{array}{l}\text { Structural and } \\
\text { understanding }\end{array}$ & $*$ \\
\hline Visualization & $*$ & $*$ \\
\hline Algebraic skills & & + \\
\hline Creativity & & + \\
\hline Making and testing conjectures & & + \\
\hline Building visual concepts & & + \\
\hline Concepts visualization & & - \\
\hline Analytics abilities & & + \\
\hline
\end{tabular}

Note:

1. * means that there is no significant correlation between ability in visual representation and levels of visual thinking observed from mathematics competencies;

2. + means that the competency is better than......;

- means that no better one from other

The correlation between visual representation and visual thinking within and between mathematics abilities based on analytic assumption could become an ability or competency measure in geometry especially for setting learning activity. For example, there is a belief system when students have good performance in visual thinking, their mathematics competencies are better than those who work based on visual representation. However, for analytic abilities, there is difference between students who are still in visual representation oriented and those who have higher visual thinking level.

\section{DISCUSSION}

On the basis of the written tests, we conjecture that visual representation competencies are good predictors of visual thinking. Rive's model of visual representations is good predictors of both visual representation and visual thinking. In response to students who gave different answers (not right), they tried to seek higher level integration of mathematics abilities in understanding mathematics problems. Heightened visual thinking is possible, and common, as a result of questions about an object to be manipulated.

Visual thinking of geometry objects is a different process with students having to integrate the elements for solving problems. Visual production is often accompanied by perception or constructed representations which appear to closely resemble features of the image being formed. Repeatable unit items such as triangles, squares, and other polygons, cubes, pyramids, and icosahedrons played a major part in students' integration of data into perception, and a coherent image, of a geometry object. Generally, much of mathematics competencies involve the construction of analytic units, whether it is in term of formula, or symbol manipulating.

Students' talk in explaining and questioning is often hesitant. We hypothesize this because students are thinking and explaining alternately. In the questions we have given, the thinking involves searching for complete features of geometric objects or algebraic representations, and it seems to be just this focus of attention that inhibits solution at that moment.

It is difficult - perhaps impossible - to both talk about an object and inspect deeply an image of it, or look deeply at it for visual information, at the same time. We have found no evidence for this in the psychological literature. However, there is currently a debate about the independence of auditory and visual codes [18][19][20][21][22][23] that suggest the likelihood of such difficulty. Evidence from mathematically advanced students with varying levels of attainment shows that such difficulties occur in practice and are probably common.

The students in this research had difficulty in speaking fluently as they examined deep features of objects or images. To us, it indicates that such fluent verbal descriptions do not involve inspection or perception of deep features of images or objects. In other words, fluency of verbal description is generally incompatible with concurrent deep perception or imagery. Someone who describes such deep features fluently may have previously examined them deeply. However, they are not examining deep features at the same time as they talk fluently.

If we, as teachers, explain mathematics in a clear, fluent manner, the chances are we are not thinking about deep visual features of the mathematics at the same time. We suspect that in the process of organizing and delivering a classroom lesson, many - perhaps most - mathematics teachers' focus of attention is on the way in which the lesson is proceeding and not on deeper features of mathematical thought. Put simply, we can prepare a lesson on polyhedra, for example, and talk fluently about the properties of polyhedra because of our preparation. What we claim, is that at that moment of fluent delivery, we the teacher - are not inspecting deep properties of the polyhedra. In other words, we are concentrating on our delivery and not on our thought processes.

Students' hesitancy in explanation or questioning exists and is probably common. The reasons for this deal with the extreme difficulty that students have in talking about deeper features of objects or images at the exact same time. As a result, we, as teachers, should not try to prevent students being hesitant, but rather recognize this hesitancy for what it is prolonged deep perception or imagination. Most student have far more mental ability than their words, or their math homework. It is important to keep a good measure of humility, and not to assume we know what is going on in their minds. Forcing them to talk in ways that are not natural for them 'can' help them think clearly, but it 'can' and often have the effect of blocking them from thinking for themselves [24].

Interaction between students, through asking questions and receiving answers, and in arguing about different images, is a strong stimulus to the formation of a satisfactory and stable mental image. In the group discussions, there were many instances of students, through group interactions, achieving image formation and perception that were at a higher level than indicated on written tests, and at a higher level than indicated by their determined levels. We conclude that such group discussions can form a significant tool for assisting student to gain heightened geometric perception and imagery of polyhedra in a relatively short time span.

When students are inspecting concrete objects and reporting on their perceptions, or asking questions about 
hidden objects and reporting on their imagery, they spend a lot of time going back and forth between global and local points of view: between trying to describe the object as a whole, and trying to describe its parts. The question of what one processes first - global or local information, the whole or the parts - has been addressed systematically [25]. Their basic finding can be summarized as follows: there are specific areas of the brain involved in co-ordinating visual data about global features of systems of objects, areas involved in co-ordinating data about local features, and a mechanism for changing the rate at which data arriving at each of these areas is analyzed. Their discussion centers around four basic questions:

First, what is processed first, features of parts (more local forms) or features of their wholes (more global forms)? Second, to what degree can known properties of the visual sensory system account for the perceptual organization of parts and their wholes? Third, to what degree can differences in performance between parts and their wholes be attributed to attentional versus perceptual processes? Fourth, what determines the interaction between parts and their wholes that eventually produces a coherent perceptual scene? (p. 301)

The problem for visual perception of 3-dimensional objects such as polyhedra is what one takes as a whole and what as a part. It is fairly straightforward for anyone to perceive the triangular faces of an icosahedron, for example, as parts of the overall object: they are clearly delineated by well-marked edges. But what about a pentagonal pyramid? Even if one does see a pentagonal pyramid as a part of an icosahedron, a slight rotation of the icosahedron seems to bring a new pyramid into view and make the first disappear. So much for visual perception! Is the pyramid there or isn't it? The point is that for a relatively complex object like an icosahedron it is possible to see various "parts", but these parts are not always self-evident, and time and patience may be required for their perception.

In the visual perception of differing parts of an icosahedron there does not seem to be just a simple co-ordination of global and local data: rather there seems to be a constructive process, by which an individual makes sense of data - both global and local - to construct a global perception of the object as a sum of relatively local parts. At the simplest perceptual level the icosahedron is a non-overlapping sum of congruent triangles. But that does not describe it easily because we do not have global information on how the triangles fit together. At a higher perceptual level the icosahedron is a non-overlapping sum of two pentagonal pyramids, rotated with respect to each other, and a polygonal band of alternating triangles. This latter description is also a local-global description, but it utilizes higher level parts and a simpler connection of those parts. This seems to be the preferred way for students to describe such polyhedra in order to form a mental image.

Strictly speaking, the visual perception of a pentagonal pyramid as a part of an icosahedron does not seem simply to be a question of perception alone, but also one of imagery. We hypothesize that a student has to form a pre-image of the pyramid and then see it in the physical object. It as if, upon being asked if there are pyramids in the icosahedron one forms a vague template - not quite a detailed, inspectable image - of a general pyramid, without assumptions as to the nature of its base, and then "sees" the pentagonal pyramid upon closer inspection. In looking for a pyramid in an icosahedron we postulate that a student has a similar vague image of a paradigmatic pyramid - as a cone over a polygon - and then finds perceptual data to sharpen the image template into something with fine, detailed features.

What was striking about the student's questions was their concentration on faces of polyhedra, and the ways in which faces might fit together to form identifiable sub-objects of a polyhedra. There were almost no questions on vertices and very few on edges. There were no questions asked, or information offered, on the number of edges meeting at a vertex. This is in marked contrast to an analytic description of a polyhedron: see for example, Maeder's description of the Wythoff symbol [26].

Both in visual perception and image formation, the students seem to favour a plan of seeking information about relatively regular sub-objects such as cubes and pyramids that might fit together in certain ways to give the entire polyhedron. In image formation, this is a sort of mental "chunking" procedure in which mentally manageable sub-units of the polyhedra are built up, so allowing missing bits of the image to be filled in. We hypothesize that the students do this, rather than focus on analytic information about vertex structure, so as to reduce the cognitive load of image formation. This is not surprising when we remember that, that images are formed from pre-conceived perceptual units [16].

We conjecture that the analytical abilities associated with increasing levels are correlated with increasing abilities in visual perception of objects such as polyhedra. However, ability in image formation in 3-dimensional geometry appears to be associated with a holistic approach of building a mental picture through the process of forming mentally identifiable sub-units of an object, relating them one to another in space, and filling in missing bits. It seems to be more a synthetic than analytic process.

We suggest that the requirement to substantiate the correlation between visual levels and visual is a reliable, valid test of visual perception that can be administered to a larger number of students, at differing stages of geometric development. Further, the process of attainment of ability in image formation seems best addressed by longer term developmental studies with individual students.

\section{SAMPLE RESULT FROM THE DISCUSSION GROUPS}

This part of the experiment was carried out using concrete three dimensional shapes. Pen and paper were available to the students who were encouraged to draw the shapes during their description. After considering each object, the students stopped only when they believed they had successfully completed their oral description. Throughout the discussion the student with the shape provided information, on request, to the rest of the group. Table 4 shows the visual thinking levels and degrees of acquisition of spatial abilities of the 7 students who participated in the discussion groups. Note that although student is assigned level 2 in transition to level 3, in fact in was not possible for us to assign a clear visual representation level since there was no evidence of a clear attainment of level 2. Similarly, student is assigned level 1 in transition to level 2, but this student exhibited evidence of level 3 thought.

Student (level 2) manipulated a shape behind a screen, out of sight of students (level 3 -> 4 ), (level 3) and (level 4). One 
of the students with level 2 began with a quantitative and relevant question, but used the word "sides" rather than "faces": The student explained that if one put a cube on the ground, such that it kept its face on the ground in a fixed position, and in addition pushed the top, the required shape would be formed. This student did not take into account that just the lateral faces of a cube would change from a square to a rhombus, with the top and bottom remaining the same shape: a square. This was clear to student of level 3, who was functioning at level 4. She demonstrated an ability to understand the logic of the situation:

The students (no assigned level: level 1 -> 2 generally, but shows evidence of level 3 thought) manipulated a shape behind a screen, out of sight of students (no assigned level: level 2 -> 3 , but lacks some aspects of level 2 thought) and student (level 3 ). A student of level 3 began with a question he asked several times in group discussions. This question, which was more or less subjective, did not focus on properties of the object, and was in keeping with students' lacking some aspects of level 2 thought. A student of level 2 again asked a series of more analytical questions which indicated a functioning visual level of 2. They also involved visual discrimination in which this student tested poorly. A student of level 3 made an attempt at identification. After being unable to draw the object, the student asked a question involving symmetry, which one would expect at level 4 . This student has good spatial abilities in all areas and very good position-in-space abilities: We found that the interchange of knowledge that took place during the discussions contributed to the development of the students. This led some of them to a higher spatial level than that observed in the written test. For example, in the written test a student of level 2 presented very poor responses related to properties of shapes. This student also showed problems associated with position in space perception. On question three the student regarded tetrahedrons and square based pyramids as identical. The discussion above indicates a relatively higher achievement for this student in relation to the written test.

Observing the previous explanation, it becomes clear that group 1 used a better mathematical language than group 2 . They were able to make clear understanding when the discussion was about two-dimensional shapes (a face of the solid) or three dimensional objects. In the beginning of the discussion, without consistent information, group 2 tried to determine the shape. Also, this group used the word "side" without explaining carefully, or negotiating, what they meant.

Spatial thinking involves synthesis, an intuitive grasp of complex systems, (often missing the steps) simultaneous processing of concepts, inductive reasoning (from the whole to the parts), use of imagination and generation of ideas by combining existing facts in new ways (creative thinking). It is influenced by visualization and images and an awareness of space. Spatial, holistic and synthetic functions are thought to be associated with the right hemisphere of the brain [27]. Whereas left brain thinking is step by step linear thinking over time, right brain thinking is a holistic system where all knowledge is interconnected in space.

When left brain thinkers are asked the answer to a question, they will look for the right answer based on the facts at their disposal. When right brain thinkers are asked a question, they usually respond with some form of "Tell me more/it depends".
As all their knowledge is connected, they can see many paths to differing answers and they want more information to help them decide which path to take to the required answer.

This divergent thinking is the hallmark of creativity but may not be understood in school where achievement is often seen as having the right answer. "Because one of the attributes of right brained thinking is a non-sequential divergent form of thinking, their minds often veer into unusual and different territory. This can result in illogical or often unsubstantiated conclusions. On the other hand, they may view a problem from an entirely different angle, leading to new breakthroughs and discoveries" [28].

Visual spatial learners frequently have difficulty with language. In order to communicate their thoughts, first they have to grab particular images in their heads and place them in order. Then they have to hold them in memory. Then they have to find the words to describe their images. Then they have to hold the images of the words in order long enough to speak them aloud.

Visual spatial learners thrive on complexity and often fail at simple tasks e.g. math concepts versus times tables. Because they focus on the larger picture, they often do not know how they have arrived at a conclusion or solved a problem. They do poorly on timed tests. Also, they tend to be disorganised and have difficulty meeting time limits. This is not a behavioural issue but a significant difficulty for which they need assistance to develop appropriate strategies and skills. They need structure and predictability, clear limits and time frames and assistance with project planning. It is important that they are praised for their effort rather than concentration on achievement as it takes considerable time for them to develop organisational strategies and skills.

\section{VIII.CONCLUSION}

We must respect the differences in students and act on them positively. There are both hope and help for the right-brained visual spatial gifted students. Earlier identification and more understanding will result in less ostracism and shaming. Society will benefit from their formidable brain power as well, as we better tap into their abilities to see, take on and solve problems in fresh and creative ways [28].

Visual spatial learners are more attentive if they understand the goals of instruction. They are more cooperative at home and at school if they are allowed to give some input into decision making processes and some legitimate choices. Discipline must be private as these children are highly sensitive and easily humiliated. If they are respected they will learn to treat others with respect. These children thrive on complex, abstract ideas; they are natural pattern finders and problem solvers. Therefore, they ideally suit the types of experiences in gifted programs and activities. When they are placed in the right learning environment, where there is a good match between their learning style and the way they are taught, visual spatial learners can actualize their potential to become innovative leaders in our society [29].

The students' oral description of a certain shape depends on a combination of the students' general geometric level, their spatial ability, and their ability to express the properties of the shape using language. The results from the discussion groups show the importance of both spatial ability and language use in 
the on-going development of geometric thought. The assessment of spatial levels of thinking and spatial perception applied to three dimensional geometry confirmed the hierarchical nature of the geometric levels [30][31][32]. However the assessment of spatial perception is not hierarchical. This research shows that it is possible for a student to acquire the abilities pointed out by those levels without any regular sequence.

\section{REFERENCES}

[1] Clements, H. Douglas, and M. T. Battisda, Geometry And Spatial Reasoning, In Douglas A. Grouws (Ed.), Handbook of research on mathematics teaching and learning. USA: Macmillan, 1992.

[2] M. Rif'at, Analisis Tingkat Deduksi dan Rogoritas Susunan Bukti Mahasiswa Jurusan Pendidikan Matematika IKIP Malang, Unpublished master's thesis, PPS IKIP Malang, Malang, 1997.

[3] M. Rif'at, Pengaruh Pembelajaran Visual Dalam Rangka Meningkatkan Kemampuan Deduksi Visualistik pada Soal Berciri Visual, Unpublished doctor's dissertation, Bandung, PPS UPI Bandung, 2001.

[4] P. S. Wilson, (Ed), Research Ideas For The Classroom High School Mathematics, New York: Macmillan Publishing Company, 1993.

[5] D. A. Grouws, (Ed.). Handbook of Research on Mathematics Teaching and Learning, USA: Macmillan, 1992.

[6] A. H. Schoenfeld, (Ed.), Mathematical Thinking and Problem Solving. Hillsdale, New Jersey: LEA, 1994.

[7] D. Tall, The Transition to Advanced Mathematical Thinking: Function, Limits, Infinity, and Proof, In Douglas A. Grouws, Handbook of research on mathematics teaching and learning, USA: Macmillan, 1992.

[8] E. G. Begle, Critical Variables In Mathematics Education: Findings From A Survey of Empiric Literatur, Washington, D.C. : Mathematics Association of America, 1979.

[9] E. Galindo, (Eds.) (1995), "Visualization and students' performance in technology-based calculus," In Douglas T. Owens, Michelle K. Reed, and Gayle M. Millsaps (Eds.), Proceedings of seventeenth annual meeting for psychology of mathematics education, 2, Columbus: ERIC, 1995, pp.321-326.

[10] M. W. Matlin, Cognition (third edition), USA: Holt, Reinhart and Winston, 1994.

[11] R. M. Gagne, Kondisi Belajar dan Teori Pembelajaran, Translated by Munandir, 1989, Jakarta: DIKTI, 1984.

[12] M. Mikio, "New Perspective For Teaching Proof," Paper presented at The 24 th conference of the international group for the psychology of mathematics education, Hiroshima, 2000.

[13] P. Tsamir, and N. Mandel, "The intuitive rule same A-same B: the case of area and perimeter," Paper presented at The 24 th conference of the international group for the psychology of mathematics education, Hiroshima, 2000.

[14] J. F. Mundy, and D. Lauten, "Learning about calculu"s, The mathematics teacher, 87 (2), 1994, pp.115-120.

[15] S. Saads, and G. Davis, Pre-Service Secondary Teachers' Visual Perception and Imagery in Three Dimensional Geometry, Pre-print, University of Southampton, UK, 1997.

[16] S. M. Kosslyn, Image and Brain: The Resolution of the Imagery Debate, Cambridge, Mass: The MIT Press, 1996.

[17] M. Rif'at, Persoalan Pendidikan Matematika, Pontianak: Romeo Grafika, 2010.

[18] A. Paivio, Dual coding theory - retrospect and current status, "Canadian Journal of Psychology - Revue Canadienne de Psychologie," 45(3), 1991, pp.255-287.

[19] A. Bishop, Spatial abilities and mathematics education - a review, "Educational Studies in Mathematics,"11, 1980, pp.257-269.
[20] A. Bishop, Space and Geometry, In "Acquisition of Mathematics Concepts and Process," In R. Lesh and M. Landau (Eds.), New York: Academic Press, 1983, pp.175-203.

[21] V. A. Thompson, and A. Paivio, Memory for pictures and sounds independence of auditory and visual codes, "Canadian Journal of Experimental Psychology - Revue Canadienne de Psychologie Experimentale," 48(3), 1994, pp.380-398.

[22] D. Partridge, Language and vision - a single perceptual mechanism, “Artificial Intelligence Review," 9(4-5), 1995, pp.291-303.

[23] M. A. Brandimonte, G. J. Hitch, and D.V.M. Bishop, Verbal recoding of visual-stimuli impairs mental image transformations, "Memory \& Cognition," 20(4), 1992, pp.449-455.

[24] W. Thurston, Precision in writing/ thinking/ programming, In D. Epstein (moderator) Archives of MATHEDU,. Retrieved February 12, 1997, from URL:archives.math.utk.edu/hypermail/mathedu/feb97/0121.html

[25] L. C. Robertson, and M. R. Lamb, Neurophysiological contributions to theories of part/whole organization, "Cognitive Psychology," 23, 1991, pp. $299-330$

[26] R. E. Maeder, Uniform Polyhedra, 1995, URL http: //www.inf.ethz.ch/ department/ TI/ rm /unipoly/ index.html

[27] T. West, In The Mind's Eye, Prometheus Press, New York, 1991.

[28] J. Freed, Teaching Right: Techniques for Visual Spatial Gifted Children. Understanding Our Gifted, 8 (3), 1996, pp.16-19

[29] L. K. Silverman, Teaching Gifted Children With Classroom Adjustment Difficulties, Invited Address to the International Council for Exceptional Children, 1994.

[30] S. Usiskin, van Hiele levels and achievement in secondary school geometry, Final Report, Cognitive Development and Achievement in Secondary School Geometry Project, Chicago: The University of Chicago, 1982.

[31] J. Mayberry, The Van Hiele Levels of Geometric Thought In Undergraduate Preservice Teachers, "Journal for Research in Mathematics Education," 14(1), 1983, pp.58-69.

[32] A. Gutiérrez, A. Jaime, and J. M. Fortuny, An Alternative Paradigm to Evaluate the Acquisition of the van Hiele levels, "Journal for Research in Mathematics Education,” 22 (3), 1991, pp.237 
